\title{
The Effect of Alloying Elements on the
}

\section{Solubility of Oxygen in $\delta$-iron*}

\author{
By Kiyoshi NISHIKAWA, ${ }^{* *}$ Akihiko KUSANO, ${ }^{* * *}$ Köin ITō, ${ }^{* *}$ and Kōkichi SANO ${ }^{* *}$
}

\section{Synopsis}

Effects of manganese, silicon, chromium, vanadium, and nickel on the solubility and their interaction coefficients with oxygen in $\delta$-iron were determined by the direct solid-liquid equilibration muthod, in which a crucible was lowered very slowly under purified argon gas in a Tamman furnace, and the equilibrium compositions between solid iron and liquid were measured.

The relation of the partition ratio of oxygen in $\mathrm{Fe}-\mathrm{O}$ system, $L_{0}^{\prime}$, and in $\mathrm{Fe}-\mathrm{X}-\mathrm{O}$ system, $L_{0}$, is expressed by the following equation:

$$
\log L_{0}=\log L_{0}^{\prime}+\log \left(f_{i}^{(\mathrm{X})} / f_{s}^{(\mathrm{X})}\right)
$$

where, the $f_{s}^{(\mathrm{X})}$ and $f_{\mathrm{o}}^{(\mathrm{X})}$ are the interaction coefficients in solid and liquid iron, respectively. The interaction coefficients in solid iron were calculated as follows:

$$
\begin{array}{ll}
\log f_{s}^{(\mathrm{Mn})}=-1.83[\% \mathrm{Mn}] & (<0.15 \%), \\
\log f_{s}^{(\mathrm{Si})}=-12.14[\% \mathrm{Si}] & (<0.1 \%), \\
\log f_{s}^{(\mathrm{Cr})}=-0.23[\% \mathrm{Cr}] & (<0.5 \%), \\
\log f_{s}^{(\mathrm{V})}=-1.71[\% \mathrm{~V}] & (<0.3 \%), \text { and } \\
\log f_{s}^{(\mathrm{Ni})}=0.105[\% \mathrm{Ni}] & (<1.0 \%) .
\end{array}
$$

\section{Introduction}

The formation of non-metallic oxide inclusions in steel is closely related to the interaction between oxygen and alloying elements such as manganese and silicon. Although the effects of alloying elements on the activity coefficients of oxygen in liquid iron have been measured with reasonable accuracy, these in solid iron have not been investigated enough. Nonmetallic inclusions change their composition in solid iron during annealing at high temperatures. ${ }^{1)}$ Therefore, it is desirable to measure the effects of alloying elements on the solubility of oxygen in solid iron. The interaction between nitrogen ${ }^{2-8)}$ or sulphur ${ }^{9)-11 \text { ) }}$ and alloying elements has been investigated under the direct equilibrium between gas and solid iron. However, this method has many experimental difficulties. For example, extremely long time is needed for the attainment of equilibrium, precise adjusting of the gas composition is hard to obtain, and large errors are anticipated due to impurities in the solid. Wada and Saito estimated thermodynamically ${ }^{12}$ ) the difference of the atomic interaction between solid and liquid iron. Wada et al. calculated the interaction parameter of $\mathrm{Fe}-\mathrm{C}-\mathrm{X}$ system and $\mathrm{Fe}-\mathrm{N}-\mathrm{X}$ system. ${ }^{13)}$

In the previous work, ${ }^{14)}$ a simple yet reliable technique for the direct solid-liquid equilibration was established: a crucible containing properly selected sample is lowered very slowly under purified argon gas in a Tamman furnace, and the equilibrium is attained between solid and liquid iron by utilizing the temperature gradient in the furnace; the partition ratio between solid and liquid is determined from analysis and the solubility of oxygen in $\delta$-iron is calculated from it. In the present work, manganese, silicon, chromium, vanadium, and nickel were investigated for their effects on the partition ratio of oxygen, and the interaction coefficients of these alloying elements with regard to oxygen in $\delta$-iron were determined.

\section{Experiment}

Experimental apparatus is the same as the one used in the previous work. ${ }^{14)}$ Electrolytic iron, the iron oxide, and the alloying elements were put in the crucible, and the experiment was done under the condition of oxygen saturation so that slag was always on the surface of liquid. In this experiment, it is necessary that oxygen is dissolved perfectly both in liquid and solid iron; no oxide must exist. There were, however, a few oxides in solid phase as shown in Photos. 1 and 2.14) Oxides in liquid phase in Photo. 2 can be considered to have been formed during solidification. Therefore it can be said that oxides do not exist during equilibrium between solid and liquid

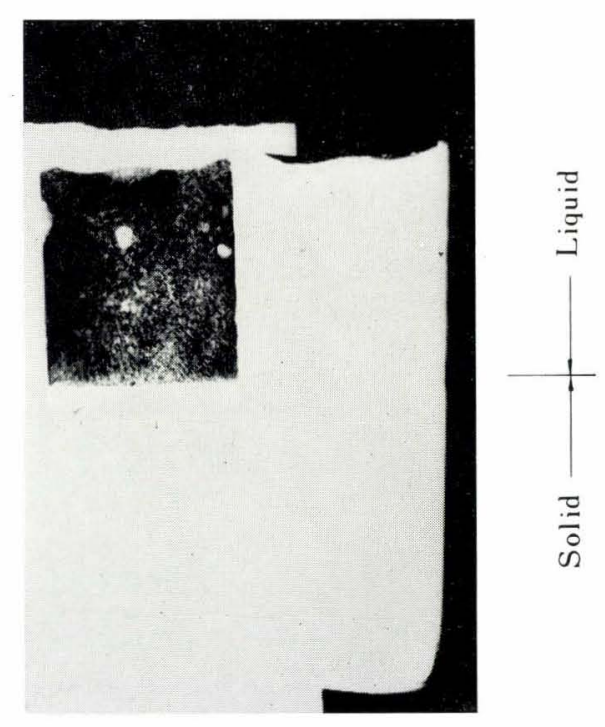

Photo. 1. Macrophotograph of sulphur print (left) and its specimen (right) $(\times 1)(2 / 3)$

\footnotetext{
* Received August 21, 1969.

** Department of Metallurgy, Faculty of Engineering, Nagoya University, Chikusa-ku, Nagoya 464.

*** Department of Metallurgy, Faculty of Engineering, Nagoya University. Now at Tobata Works, Yawata Iron \& Steel Co., Ltd., Kitakyushu 805 .
} 


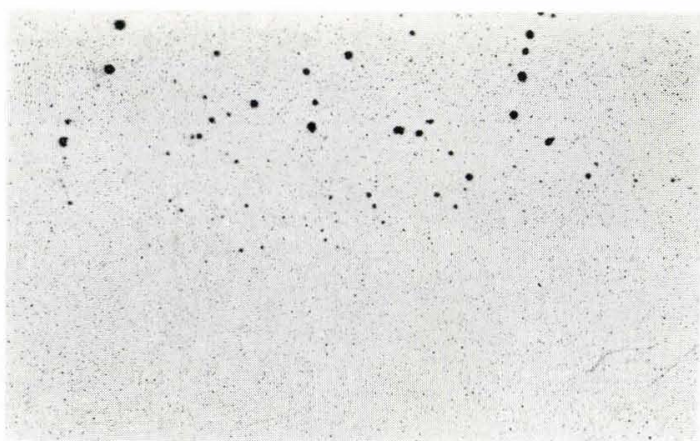

1

Photo. 2. Microphotograph of the liquid-solid interface $(\times 100)(2 / 3)$

iron; even if they do, they will rise up to the surface in such a long time as this experiment takes.

Materials added were as follows:

(1) electrolytic manganese (of a purity $>99.9 \%$ ),

(2) electrolytic nickel

(of a purity $>99.98 \%+$ cobalt),

(3) metallic silicon

(of a purity $>98 \%$ ),

(4) metallic vanadium, and

(5) electrolytic chromium

(of a purity $>99.7 \%$ ).

The following materials were also added in order to adjust the concentration of oxygen :

(1) ferric oxide (of a purity $>99 \%$ ),

(2) manganese dioxide (of a purity $>99.0 \%$ ),

(3) nickel oxide that was made from nickel nitrate by heating in an oxygen atmosphere at $300^{\circ}$ to $600^{\circ} \mathrm{C}$,

(4) silicic anhydride, and

(5) vanadium pentoxide (of a purity $>99.0 \%$ ).

The methods of analysis were ;

(1) oxygen: vacuum fusion method (when the sample contained an appreciable amount of manganese, however, the Matoba and Gunji's method ${ }^{15)}$ of co-fusion with a small quantity of tin was used; this method is known to be effective to cut down the error due to the adsorption of carbon monoxide gas

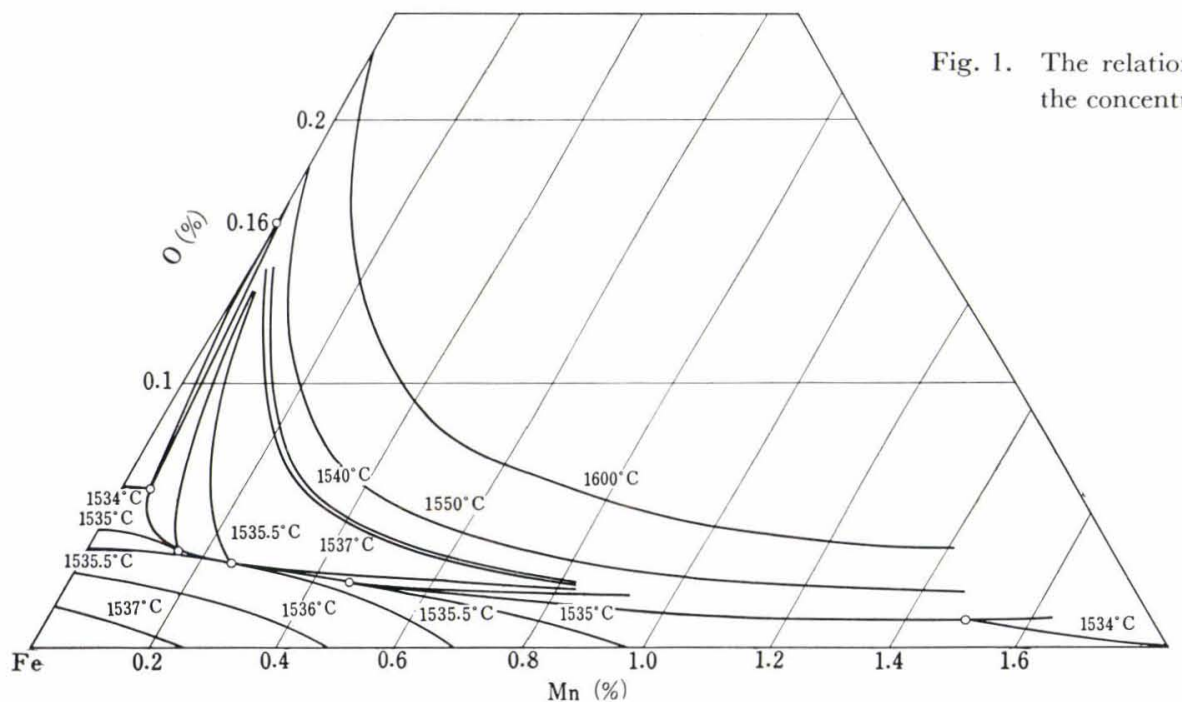

Fig. 2.

The diagram of $\mathrm{Fe}-\mathrm{Mn}-\mathrm{O}$ system to the evaporated manganese film.),

G 1213),

(2) manganese: absorptiometric method (JIS,

(3) silicon: molybdenum blue absorptiometric method,

(4) chromium: diphenylcarbazide absorption method when below $1 \%$,

(5) nickel : dimethyl-glyoxime method, and

(6) vanadium: phospho-vanadotungstenate

method.

\section{Experimental Results}

\section{1. $\mathrm{Fe}-\mathrm{Mn}-\mathrm{O}$ System}

As the freezing temperature in $\mathrm{Fe}-\mathrm{Mn}-\mathrm{O}$ system was not known, it was determined from the cooling curve of liquid $\mathrm{Fe}-\mathrm{Mn}$ alloys saturated with oxygen. Figure 1 shows the relation between the freezing temperature and the concentration of manganese. In Fig. 1, there is a temperature peak at near $0.3 \%$ manganese. This phenomenon can be explained by the $\mathrm{Fe}-\mathrm{Mn}-\mathrm{O}$ system diagram, Fig. 2 as follows. The thick solid line, which is due to the experimental values in Fig. 1, starts off at the point of $0 \%$ manganese and $0.16 \%$ oxygen at $1528^{\circ} \mathrm{C}$, and follows the valley between the two hills as the concentration of manganese increases. Until the point of $0.3 \%$ manganese, this line is in where the isotherms are congested and the temperature rises rapidly. After this point, however, the isotherms are sparse and the temperature falls gradually.

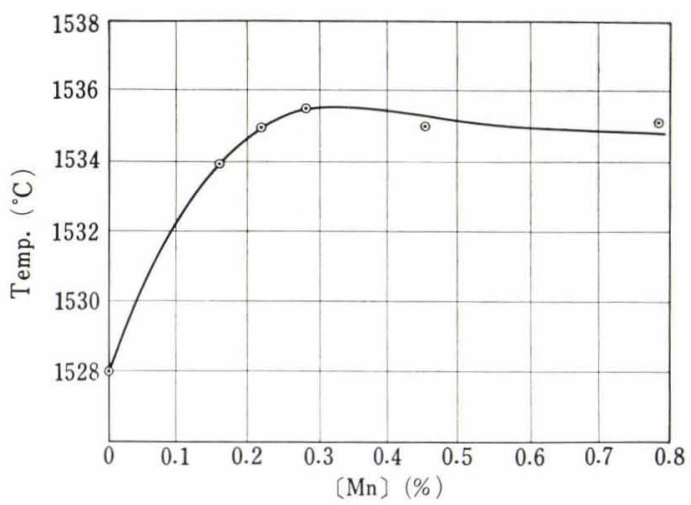

Fig. 1. The relation between the freezing temperature and he concentration of manganese in $\mathrm{Fe}-\mathrm{Mn}-\mathrm{O}$ system 
The effect of manganese on the solid-liquid partition ratio $L_{\mathrm{o}}\left(L_{\mathrm{o}}=C_{s} / C_{l}\right.$, where $C_{s}$ and $C_{l}$ are the compositions in solid and liquid iron respectively) is shown in Fig. 3. In it, it will be seen that $\log L_{\mathrm{o}}$ increased linearly up to $0.1 \%$ manganese, becoming constant above this point. The experimental values of this case were plotted in $\mathrm{Fe}-\mathrm{Mn}-\mathrm{O}$ diagram, which is shown in Fig. 4. The solid circle gives the composition of the liquid phase, and the open circle that of the corresponding solid phase. The composition of the liquid phase is on the cooling curve of Fig. 2, which was determined under the oxygen saturation condition. The broken line represents the probable solidus surface boundary as estimated by connecting with a straight line the point $0.012 \%{ }^{14}$ ) oxygen (of solid phase at $1528^{\circ} \mathrm{C}$ ) on the $\mathrm{Fe}-\mathrm{O}$ ordinate with the point $0.4 \%$ manganese (of solid phase at $1528^{\circ} \mathrm{C}$ ) on the $\mathrm{Fe}-\mathrm{Mn}$ ordinate. The oxygen concentrations of solid phase in the present work are considered to fall on this surface. The experimental value had a large error when the concentration of manganese was high, because then it was often that the magnesia crucible or semifused alumina sheath for the thermocouple were attacked, and the composition of the slag floating on

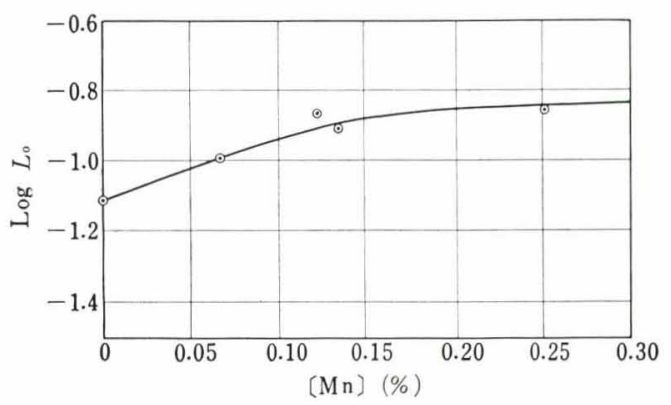

Fig. 3. The effect of the concentration of manganese in solid phase on the partition ratio of oxygen

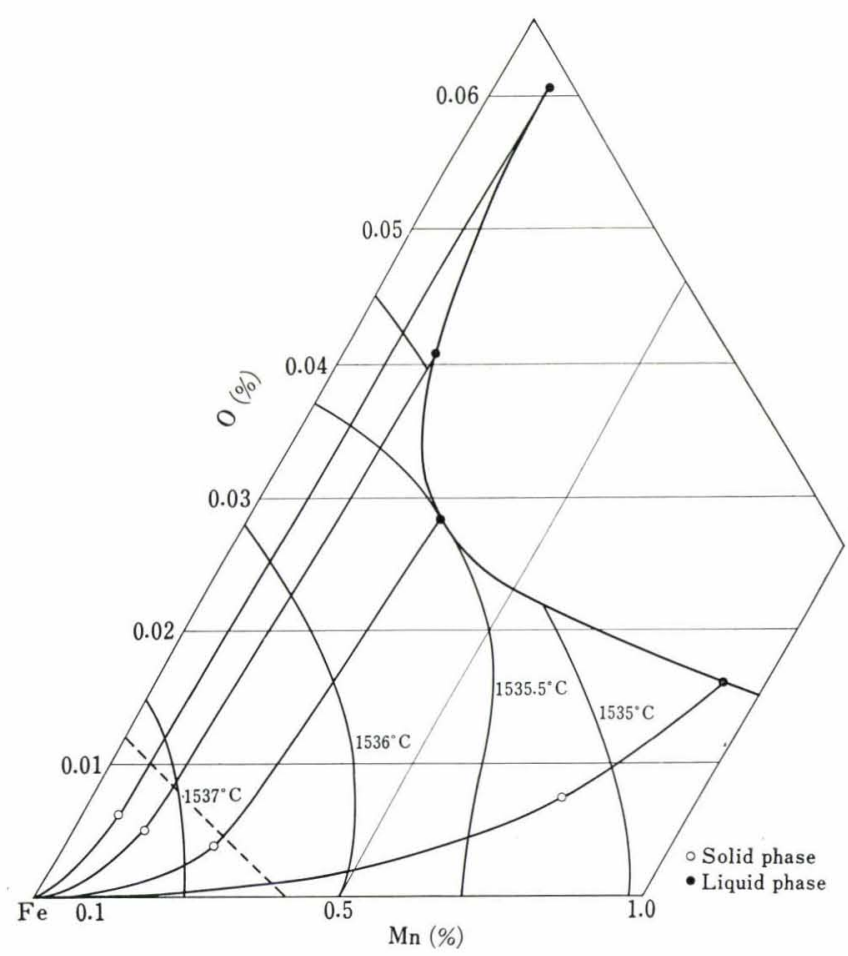

the liquid metal became to contain oxides that were not of the $\mathrm{Fe}-\mathrm{Mn}-\mathrm{O}$ system.

The $L_{\mathrm{o}}$ may, of course, depend on the temperature. However, assuming that both the solidus and the liquidus surfaces, falling down from the corner of pure iron in $\mathrm{Fe}-\mathrm{X}-\mathrm{O}$ system diagram, are conical or ellipsoidal with a respective generator line that passes through the same point of $1538^{\circ} \mathrm{C}$ that is the melting point determined in the previous work, ${ }^{14)} L_{\mathrm{o}}$ can be considered independent of the temperature and a constant. This assumption is reasonable in as much as the solidus and liquidus lines of the $\mathrm{Fe}-\mathrm{O}$ system have been shown to be linear in the previous work. ${ }^{14)}$ The dependence of $L_{0}$ on the temperature in the present work is therefore negligible. These results seem applicable within the temperature range of $\delta$-iron.

\section{Fe-Ni-O, Fe-Si-O, Fe-Cr-O, and $\mathrm{Fe}-\mathrm{V}-\mathrm{O}$ System Nickel}

Nickel seems to have less effect on the oxygen in iron, probably because it is chemically similar to iron. As shown by Sakao and Sano, ${ }^{16)}$ the interaction parameter of nickel on oxygen is

$$
e_{\mathrm{o}}^{\mathrm{N} 1}=0.005\left(<25 \% \mathrm{Ni} \text { and at } 1600^{\circ} \mathrm{C}\right)
$$

and is positive. It follows that the behavior of nickel on oxygen is different from those of chromium, manganese, silicon, or vanadium. Figure 5 shows the effect of nickel on the partition-ratio of oxygen, $\log L_{0}$ : it does not change so much, even decreasing slightly as the concentration of nickel increases and becoming constant for over $1 \% \mathrm{Ni}$, contrary to the cases of chromium, manganese, silicon, and vanadium.

\section{Silicon}

Silicon's strong affinity with oxygen lowers the oxygen concentration in liquid iron extremely. If the concentration of silicon is above $0.1 \%$ the concentration of oxygen in solid iron becomes extremely low. This results in a larger error in the oxygen analysis. The experiment was, therefore, carried out for below $0.1 \%$ silicon. Figure 6 shows the relation between the concentration of silicon in solid phase and the partition ratio of oxygen, $\log L_{0}$. Its gradient is

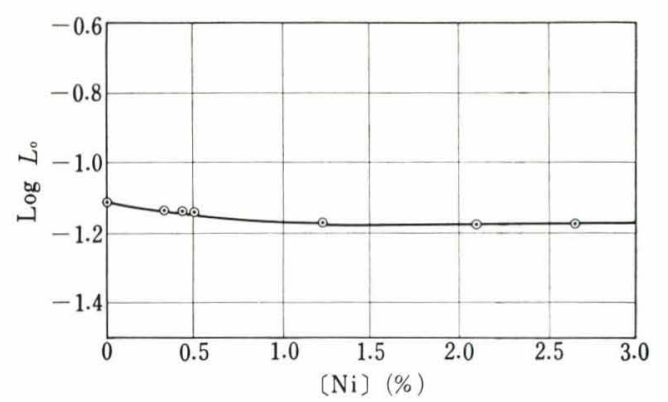

Fig. 5. The effect of the concentration of nickel in solid phase on the partition ratio of oxygen

Fig. 4.

The compositions of solid and liquid phases at equilibrium in $\mathrm{Fe}-\mathrm{Mn}-\mathrm{O}$ system 


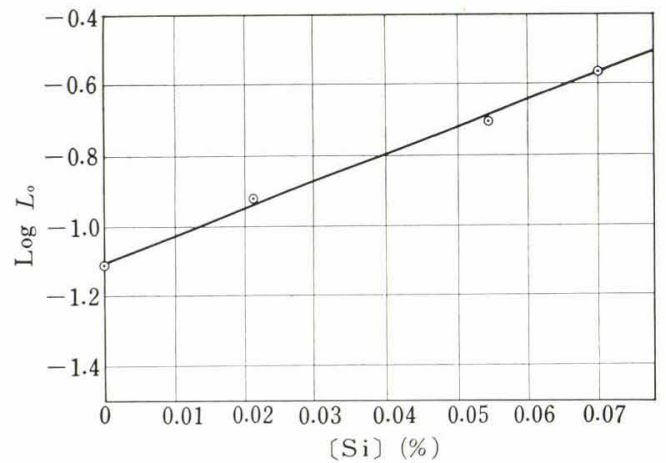

Fig. 6. The effect of the concentration of silicon in solid phase on the partition ratio of oxygen

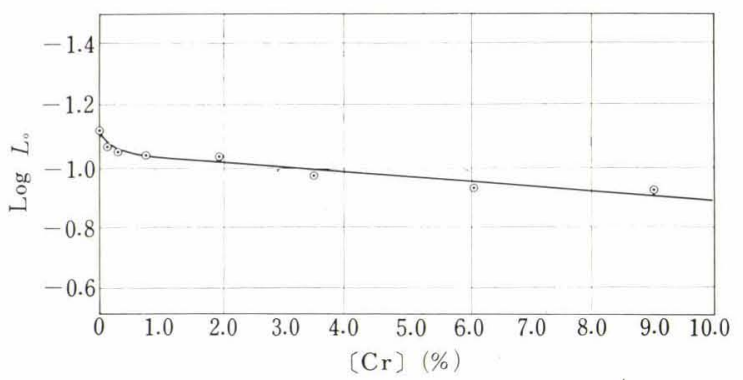

Fig. 7. The effect of the concentration of chromium in solid phase on the partition ratio of oxygen

steeper than others'. In the range of low concentration of silicon, the relation of $\log L_{o}$ with the concentration of silicon is linear.

\section{Chromium}

The relation between the partition ratio of oxygen, $\log L_{0}$, and the concentration of chromium in solid iron is shown in Fig. 7. Though the partion ratio increases as the concentration of chromium increases, the increase is less than with other elements. It becomes constant above 1\% chromium.

\section{Vanadium}

Vanadium is chemically like chromium. The relation between the partition ratio of oxygen, $\log L_{0}$, and the concentration of vanadium in solid iron is shown in Fig. 8. Below $0.2 \%$ vanadium, its tendency resembles to that of manganese: it increases linearly.

\section{Discussion}

As shown in the previous work, ${ }^{14)}$ the partition ratio of oxygen does not change with the change of the concentration of oxygen in liquid phase. In other words, it is independent of temperature. Therefore, even when the alloying elements are added, this assumption is considered to be held, and the partition ratio, $\log L_{0}$, is considered approximately independent of the temperature.

In the present work, the influences of impurities or alloying elements in steel have on the partition ratio of oxygen have been shown as summarized in Fig. 9 for the range of low concentrations. As seen in this figure, the behaviour of nickel is quite different from that of other elements, i.e., with the increase of the concentration, the partition ratio decreases. This may

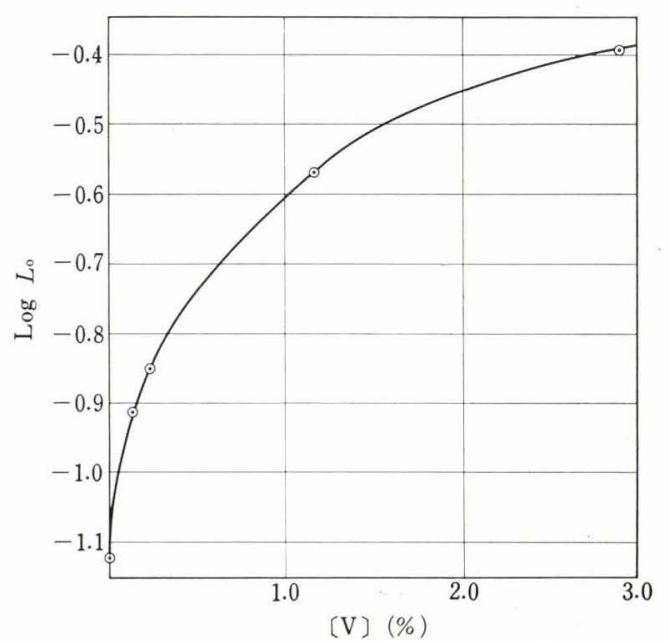

Fig. 8. The effect of the concentration of vanadium in solid phase on the partition ratio of oxygen

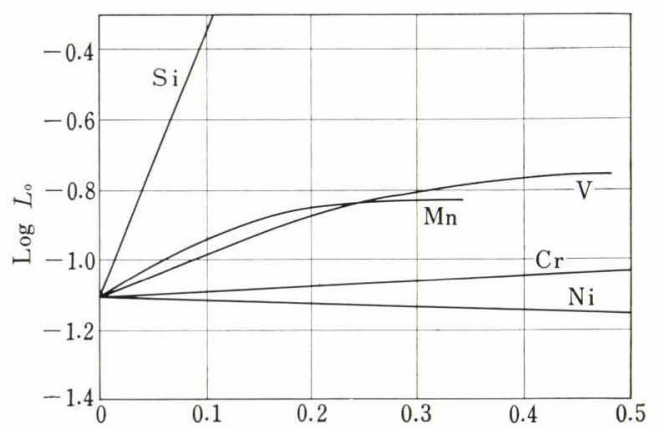

〔X〕 $(\%)$

Fig. 9. The effect of alloying elements in solid phase on the partition ratio of oxygen

be explained by introducing the interaction coefficients in solid iron in the following way:

\section{FeO System}

Under equilibrium between the oxygen in liquid iron, $\underline{\mathrm{O}}(l)$, and that in solid iron, $\underline{\mathrm{O}}(s)$, the following equations hold:

$$
\begin{aligned}
\underline{\mathrm{O}}(l) & \rightleftharpoons \underline{\mathrm{O}}(s), \\
a_{l} & =f_{l}^{\prime} \cdot[\mathrm{O}]_{l} \\
a_{s} & =f_{s}^{\prime} \cdot[\mathrm{O}]_{s}
\end{aligned}
$$

where, $a_{l}$ and $a_{s}$ : the activities of oxygen in liquid and solid iron, respectively, and

$f_{l}^{\prime}$ and $f_{s}^{\prime}:$ the activity coefficients in liquid and solid iren, respectively,

taking the state of infinitely dilute solution as standard.

The chemical potentials in liquid and solid iron are :

$$
\begin{aligned}
& \mu_{l}=\mu_{\imath}^{\circ}+R T \ln a_{l} \\
& \mu_{s}=\mu_{s}^{\circ}+R T \ln a_{s}
\end{aligned}
$$

where, $\mu^{\circ}$ : the constant.

If the equilibrium between liquid and solid iron is maintained, their chemical potentials must be equal, i.e.,

$$
\mu_{l}=\mu_{s} .
$$


Therefore,

$$
\begin{aligned}
& \left(\mu_{l}^{\circ}-\mu_{s}^{\circ}\right) / R T \\
& \quad=\ln \left(a_{s} / a_{l}\right) \\
& \quad=\ln \left\{\left(f_{s}^{\prime} \cdot[\mathrm{O}]_{s}\right) /\left(f_{l}^{\prime} \cdot[\mathrm{O}]_{l}\right)\right\} \\
& \quad=\ln \left(f_{s}^{\prime} / f_{l}^{\prime}\right) \cdot L_{o}^{\prime} .
\end{aligned}
$$

The above equation is finally written as

$$
L_{o}^{\prime}=\left(f_{i}^{\prime} \mid f_{s}^{\prime}\right) \exp \left[\left(\mu_{l}^{\circ}-\mu_{s}^{\circ}\right) / R T\right] \ldots
$$

\section{2. $\mathrm{Fe}-\mathrm{X}-\mathrm{O}$ System}

In the same manner the following equations are obtained for the $\mathrm{Fe}-\mathrm{X}-\mathrm{O}$ system,

$$
\begin{aligned}
\underline{\mathrm{O}}(l)_{\mathrm{X}} & \rightleftarrows \underline{\mathrm{O}}(s), \\
a_{l} & =f_{l}^{\prime} \cdot f_{l}^{(\mathrm{X})} \cdot[\mathrm{O}]_{l(\mathrm{X})} \\
a_{s} & =f_{s}^{\prime} \cdot f_{s}^{(\mathrm{X})} \cdot[\mathrm{O}]_{s(\mathrm{X})}
\end{aligned}
$$

where, $f_{l}^{(\mathrm{X})}$ and $f_{s}^{(\mathrm{X})}$ : the interaction coefficients of the element $\mathrm{X}$ with regard to the oxygen in liquid and solid iron, respectively.

Since

$$
\begin{aligned}
& \mu_{l}=\mu_{s} \\
& \begin{aligned}
\left(\mu_{l}^{\circ}-\mu_{s}^{\circ}\right) / R T \\
=\ln \left(a_{s} / a_{l}\right) \\
=\left\{\left(f_{s}^{\prime} \cdot f_{s}^{(\mathrm{x})} \cdot[\mathrm{O}]_{s(\mathrm{X})}\right) /\left(f_{l}^{\prime} \cdot f_{l}^{(\mathrm{x})} \cdot[\mathrm{O}]_{l(\mathrm{X})}\right)\right\}
\end{aligned}
\end{aligned}
$$

Eq. (8) becomes

$$
\begin{aligned}
L_{\mathrm{o}} & =\left(f_{l}^{(\mathrm{X})} / f_{s}^{(\mathrm{X})}\right) \cdot\left(f_{i}^{\prime} \mid f_{s}^{\prime}\right) \exp \left(\mu_{i}^{\circ}-\mu_{s}^{\circ}\right) / R T \\
& =\left(f_{l}^{(\mathrm{X})} / f_{s}^{(\mathrm{X})}\right) L_{\mathrm{o}}^{\prime} \ldots \ldots \ldots \ldots \ldots \ldots \ldots \ldots \ldots \ldots \ldots \ldots \ldots \ldots \ldots \ldots \ldots \ldots \ldots \ldots \ldots
\end{aligned}
$$

Taking the logarithm of the both sides of the above equation,

$$
\log L_{o}=\log L_{o}^{\prime}+\log \left(f_{l}^{(\mathrm{X})} / f_{s}^{(\mathrm{X})}\right)
$$

Equation (10) states that the partition ratio of oxygen in an alloyed iron may be obtained by adding log $\left(f_{i}^{(\mathrm{X})} / f_{\mathrm{s}}^{(\mathrm{x})}\right)$ to $\log L_{\mathrm{o}}^{\prime}$, the partition ratio of $\mathrm{Fe}-\mathrm{O}$ system.

In the present work,

$$
\log L_{0}>\log L_{0}^{\prime}
$$

as shown in Fig. 9, with regard to chromium, vanadium, manganese, and silicon. In order to satisfy this equation, $\log \left(f_{l}^{(\mathrm{x})} / f_{s}^{(\mathrm{x})}\right)$ must be positive from Eq. (10), or $f_{l}^{(\mathrm{X})}$ must be greater than $f_{s}^{(\mathrm{X})}$. With regard to nickel, on the other hand,

$$
\log L_{\mathrm{o}}>\log L_{\mathrm{o}}^{\prime}
$$

$\log \left(f_{l}^{(\mathrm{x})} / f_{s}^{(\mathrm{x})}\right)$ must be negative, or $f_{l}^{(\mathrm{x})}$ must be smaller than $f_{s}^{(\mathrm{X})}$. It follows that whether the affinity of an element in liquid iron to oxygen be greater than that of iron, i.e., $f_{l}^{(\mathrm{x})}<1$, or smaller, i.e., $f_{l}^{(\mathrm{x})}>1$, its effect should increase in solid iron.

As shown in Fig. 9, when the concentration of alloying elements is low, the relation between $\log L_{\mathrm{o}}$ and the concentration is linear, so that

$$
\begin{aligned}
\log L_{\mathrm{o}} & =\log L_{\mathrm{o}}^{\prime}+\log \left(f_{i}^{(\mathrm{x})} / f_{\mathrm{s}}^{(\mathrm{x})}\right) \\
& =\log L_{\mathrm{o}}^{\prime}+\alpha[\mathrm{X}] \ldots \ldots \ldots \ldots \ldots \ldots
\end{aligned}
$$

Determining the gradient $\alpha$ in Fig. 9, one obtains log $\left(f_{l}^{(\mathrm{x})} / f_{s}^{(\mathrm{X})}\right)$ as a function of the concentration of the element X. As the interaction coefficients in liquid iron $f_{i}^{(\mathrm{x})}$ have already been measured by various investigators, ${ }^{17)} f_{s}^{(\mathrm{X})}$ can be calculated as shown in Table 1 . In the table, the ranges where the relation between $\log L_{\circ}$ and the concentration of the alloying element is linear in Fig. 9 i.e., $\alpha$ is constant, are also

\begin{tabular}{|c|c|c|c|c|}
\hline $\mathrm{X}$ & $\log \left(f_{l}^{(X)} / f_{s}^{(X)}\right)$ & $\log f_{l}^{(x)}$ & $\log f_{s}^{(X)}$ & Remarks \\
\hline $\mathrm{Mn}$ & $1.83[\mathrm{Mn}]$ & 0 & $-1.83[\mathrm{Mn}]$ & $<0.15 \%$ \\
\hline $\mathrm{Cr}$ & $0.17[\mathrm{Cr}]$ & $-0.055[\mathrm{Cr}]$ & $-0.23[\mathrm{Cr}]$ & $<0.5 \%$ \\
\hline $\mathrm{Si}$ & $12 \quad[\mathrm{Si}]$ & $-0.137[\mathrm{Si}]$ & $-12.14[\mathrm{Si}]$ & $<0.1 \%$ \\
\hline V & $1.35[\mathrm{~V}]$ & $-0.36 \quad[\mathrm{~V}]$ & $-1.71[\mathrm{~V}]$ & $<0.3 \%$ \\
\hline $\mathrm{Ni}$ & $-0.10[\mathrm{Ni}]$ & $0.005[\mathrm{Ni}]$ & $0.105[\mathrm{Ni}]$ & $<1.0 \%$ \\
\hline
\end{tabular}
shown. Here, although the $f_{l}^{(x)}$ at the equilibrium temperature of solid and liquid phase should be used, as those below $1550^{\circ} \mathrm{C}$ have not been determined, the value of $f_{i}^{(\mathrm{X})}$ at $1550^{\circ} \mathrm{C}$ was taken in its stead in the present work.

The $f_{s}^{(\mathrm{x})}$ now obtained represents the interaction coefficient of those deoxidants, with regard to oxygen in solid iron, particularly near the melting point. They were calculated from Table 1 and are shown in Fig. 10. It is seen that there are great interactions between oxygen and manganese or silicon in solid iron.

With regard to $\mathrm{Fe}-\mathrm{X}-\mathrm{Y}-\mathrm{O}$ system equations similar to those of $\mathrm{Fe}-\mathrm{X}-\mathrm{O}$ system can be obtained;

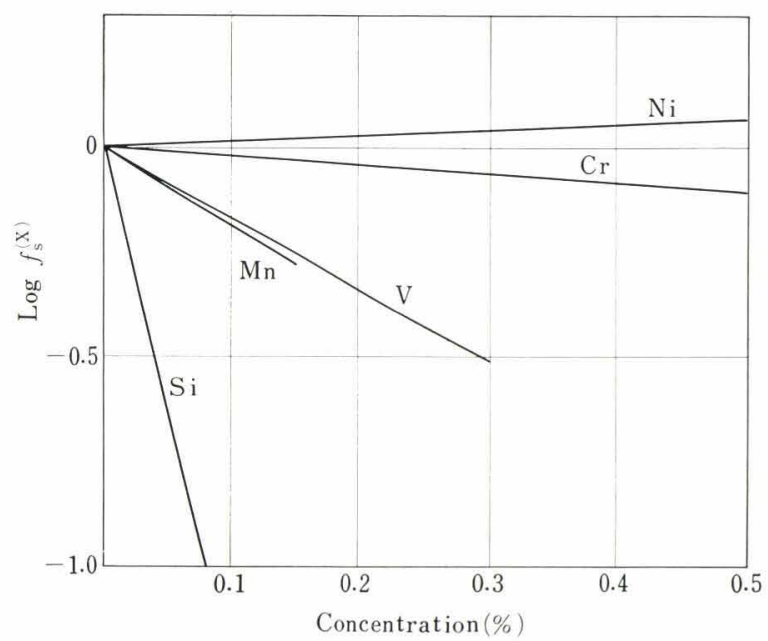

Fig. 10. The effect of the alloying elements on the interaction coefficients in $\delta$-iron

Table 1. The interaction coefficients in $\delta$-iron 


$$
\begin{aligned}
& \log L_{0}=\log L_{o}^{\prime}+\log \left(f_{l}^{(\mathrm{X})} / f_{s}^{(\mathrm{X})}\right)+\log \left(f_{l}^{(Y)} / f_{s}^{(\mathrm{X})}\right) \\
& =\log L_{o}^{\prime}+\alpha[\mathrm{X}]+\beta[\mathrm{Y}]
\end{aligned}
$$

From this equation, the partition ratio in an $\mathrm{Fe}-\mathrm{X}-\mathrm{Y}-$ $O$ system can be obtained from the experimental data of $\mathrm{Fe}-\mathrm{X}-\mathrm{O}$ system.

When $[\mathrm{Cr}]=0.097 \%$, and $[\mathrm{V}]=0.080 \%$, for example, calculation gives

$$
\begin{aligned}
\log L_{\mathrm{o}} & =\log L_{\mathrm{o}}^{\prime}+\alpha[\mathrm{V}]+\beta[\mathrm{Cr}] \\
& =-1.12+1.35 \times 0.080+0.17 \times 0.097 \\
& =-0.99 .
\end{aligned}
$$

Whereas, the experimental value was

$$
\log L_{0}=-0.75 .
$$

Although the discrepancy between them is considerable, in view of the total neglect of the interaction between vanadium and chromium and those various assumptions involved in the above equation, the agreement seems adequate. Therefore, Eq. (14) may be of a use in the practical applications, such as for a case of steel containing silicon and manganese.

\section{Summary}

The effects of the alloying elements on the solubility of oxygen in $\delta$-iron was investigated. From the relations between $\log L_{0}$ and the alloying elements, the interaction coefficients of oxygen in solid iron were calculated. From these results, it was shown that manganese and silicon, though they do not interact very much with oxygen in liquid iron, have considerable interaction in solid iron. This interaction of manganese or silicon with oxygen can be considered to increase the solubility of oxygen in solid iron; in other words, the oxides of manganese or silicon, which precipitate during solidification, remelt during soaking: it is probably by this reason that the oxides have been reported to change their form or composition.

\section{REFERENCES}

1) K. Sano, K. Itō, K. Miwa, and H. Hisada: Tetsu-to-Hagané, 54 (1968), S 513.

2) N. S. Corney and E. T. Turkdogan: JISI, 180 (1955), 344.

3) E. T. Turkdogan and S. Ignatowitz: JISI, 183 (1958), 242.

4) H. A. Wriedt and O. D. Gonzalez: Trans. AIME, 221 (1961), 532.

5) R. W. Fountain and J. Chipman: Trans. AIME, 212 (1958), 737.

6) T. Mori, K. Shinmyo, E. Ichise, and A. Morooka: J. Japan Inst. Metals, 27 (1963), 49.

7) T. Mori, K. Shinmyo, E. Ichise, and S. Koyama: J. Japan Inst. Metals, 27 (1963), 53.

8) T. Mori and E. Ichise: J. Japan Inst. Metals, 28 (1964), 145.

9) E. T. Turkdogan and S. Ignatowitz: JISI, 180 (1955), 349.

10) T. R. Mager: Trans. AIME, 230 (1964), 773.

11) H. C. Fiedler: Trans. AIME, 239 (1967), 260.

12) H. Wada and T. Saito: J. Japan Inst. Metals, 25 (1961), 159.

13) T. Wada, K. Gunji, and H. Wada: Report of Japan Society for the Promotion of Science, 19th Committee, No. 8030 (1966).

14) A. Kusano, K.Itō, and K. Sano: Tetsu-to-Hagané, 54 (1968), 553; Trans. ISIJ, 10 (1970), 78.

15) S. Matoba and K. Gunji: Tetsu-to-Hagané, 49 (1963), 758.

16) H. Sakao and K. Sano: J. Japan Inst. Metals, 26 (1962), 30.

17) Japan Society for the Promotion of Science, 19th Committee: " Recommended Equilibrium Values for Reactions in Steelmaking ", (1968), 40; 71; 91; 109, Nikkan Kôgyo Shinbunsha, Tokyo. 